\section{Cureus}

Received 01/22/2019

Review began 01/24/2019

Review ended 02/09/2019

Published 02/11/2019

\section{(๑) Copyright 2019}

Sridhara et al. This is an open access article distributed under the terms of the Creative Commons Attribution License CC-BY 3.0., which permits unrestricted use, distribution, and reproduction in any medium, provided the original author and source are credited.

\title{
Balloon-assisted Tracking of Guide Extension Catheter: A Novel Technique to Retrieve a Carotid Embolic Protection Device
}

\author{
Srilekha Sridhara ${ }^{1}$, Siamac Yazdchi ${ }^{2}$, Jamal T. Alkhatib ${ }^{3}$, Anna Berry ${ }^{3}$, Ismail A. H. Bokhari ${ }^{3}$ \\ 1. Internal Medicine, Banner Heart Hospital, Mesa, USA 2. Internal Medicine, Banner University Medical \\ Center, Phoenix, USA 3. Cardiology, Kingman Regional Medical Center, Kingman, USA
}

$\square$ Corresponding author: Srilekha Sridhara, srilekha.sridhara@bannerhealth.com Disclosures can be found in Additional Information at the end of the article

\section{Abstract}

Embolic protection devices are used to minimize the risk of stroke by preventing the migration of emboli during carotid artery stenting (CAS). After the successful conclusion of the CAS procedure, these devices are meant to be retrieved. Sometimes retrieval of the filter can be difficult. This difficulty in retrieval can be due to multiple factors such as incomplete stent expansion, stent fracture, vasospasm, and vessel tortuosity causing pseudostenoses.

In this case report, an under-expanded proximal carotid stent strut contributed to the filter not being retrievable in spite of maneuvers to retrieve the filter. An innovative approach was used; a coronary guide extension catheter was used to enhance support and balloon-assisted tracking of the extension catheter then permitted advancement of the retrieval device and ultimate retrieval of the filter. This technique to retrieve a carotid filter has not been previously described in the literature.

Categories: Cardiac/Thoracic/Vascular Surgery, Cardiology

Keywords: embolic prevention device, device retrieval, carotid artery stenting

\section{Introduction}

Carotid artery stenting (CAS) is the preferred treatment for patients with symptomatic carotid stenosis of $70 \%$ to $99 \%$ when clinical co-morbidities or anatomical factors make the patient at high risk for carotid endarterectomy (CEA). The 30-day risk for stroke is higher with stenting than with CEA. CAS is associated with a lower risk of myocardial infarction, cranial nerve palsy, and access-site hematoma compared to CEA. One of the ways to minimize the risk for stroke with CAS is the use of distal protection devices. The most commonly used device is the Emboshield filter (Abbott Vascular, Santa Clara, CA).

This case highlights how cross-specialty collaboration can help solve clinical conundrums and technical challenges. The challenge encountered in this case was difficulty in retrieving embolic filter device which got lodged in the left internal carotid artery. Knowledge of transradial angiography for coronary intervention where balloon-assisted tracking is frequently used for advancing guide catheters through vascular tortuosity was transferred and used in this carotid intervention. Balloon-assisted tracking over a guide extension catheter was performed to bail the operator out and retrieve the embolic filter device. 


\section{Cureus}

\section{Case Presentation}

A 71-year-old male with a history of hypertension, hyperlipidemia, chronic obstructive pulmonary disease, pre-diabetes, chronic smoking, and alcoholism presented with amaurosis fugax. He had suffered a previous left occipital lobe infarct. Carotid duplex and computerized tomography angiography (CTA) of the head and neck confirmed a high-grade left internal carotid artery stenosis (ICA). A five French (Fr) sheath was used for femoral access and aortic arch angiography was performed. Selective cannulation of the left common carotid artery (CCA) was done with an AR-1 catheter. Diagnostic angiography confirmed the noninvasive findings of a high-grade lesion in the left ICA (Video 1).

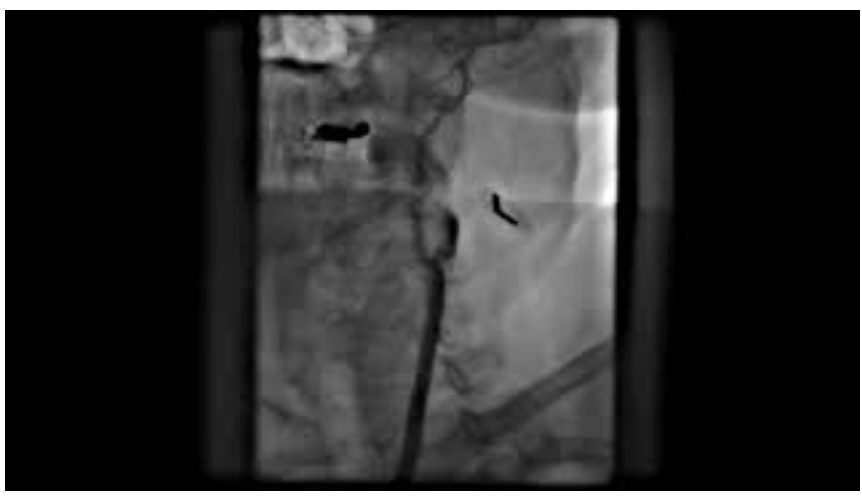

\section{VIDEO 1: Diagnostic angiography showing high grade left ICA lesion}

ICA: internal carotid artery

View video here: https://www.youtube.com/watch?v=Fvm6FqNqXIY

A seven Fr Cook Shuttle (Cook) sheath was advanced into left CCA over a glide wire advantage (Terumo). The Accunet embolic protection device (EPD) was deployed and pre-dilatation of the lesion was performed with a 4-mm balloon Maverick (Video 2).

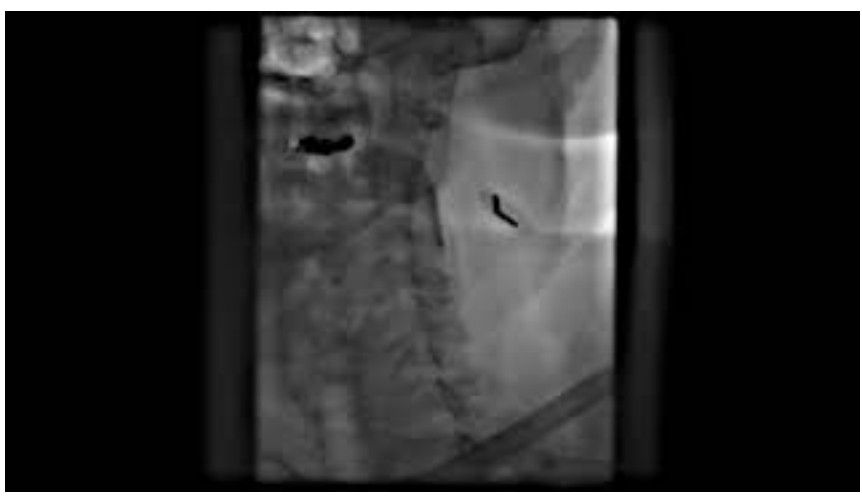

\section{VIDEO 2: Pre-dilatation of ICA lesion}

View video here: https://www.youtube.com/watch?v=1YNvRTtsIIU

An Acculink 7 x 10 x 40-mm stent was deployed without difficulty (Video 3). 


\section{Cureus}

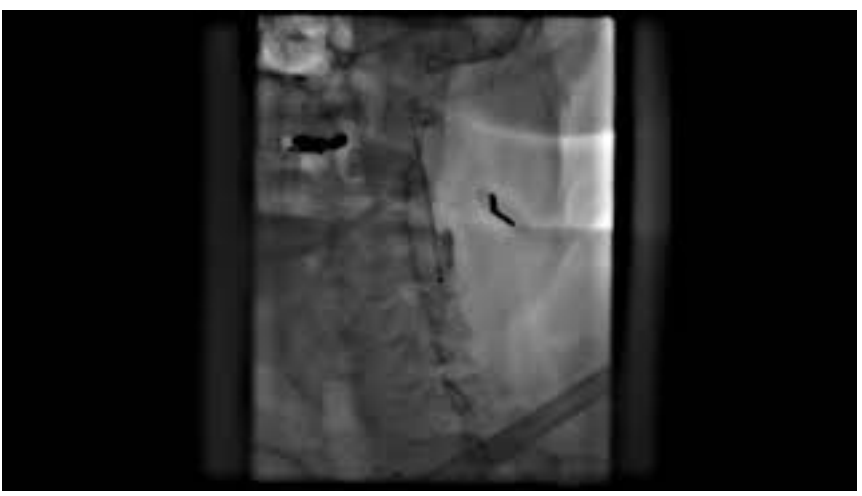

\section{VIDEO 3: Deployment of Acculink stent}

View video here: https://youtu.be/5rCQchG2n8g

Post-dilatation was performed with a 5-mm balloon (Video 4).

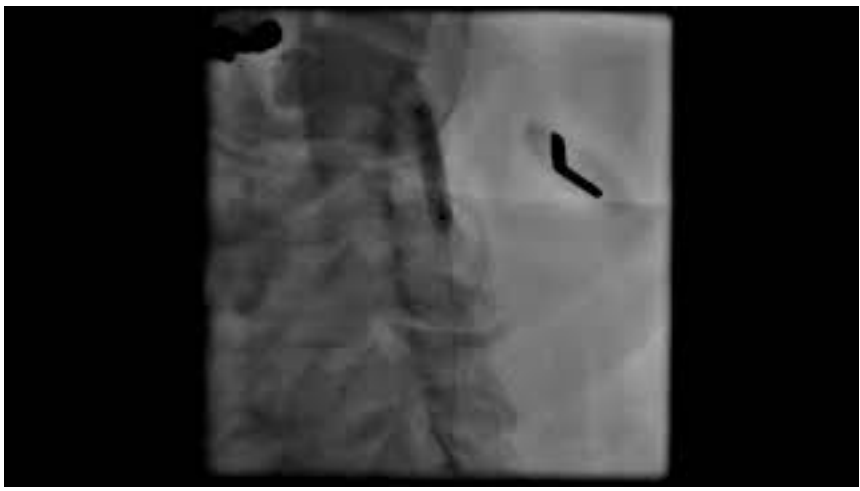

\section{VIDEO 4: Post-dilatation of the lesion/stent with $5 \mathrm{~mm}$ balloon}

View video here: https://youtu.be/zQAJU6E82wQ

Attempts to advance the EPD retrieval system beyond the origin of left ICA were unsuccessful. Even a smaller balloon was unsuccessful in crossing the under expanded proximal stent strut. Maneuvers like having the patient turn his head to the right were unsuccessful in advancing the EPD retrieval catheter.

After multiple such futile attempts, a concept that is routinely used in transradial percutaneous coronary intervention (PCI) came handy. The shuttle sheath was extended with a guide extension catheter to enhance support. A 2.5-mm balloon was advanced into this guide extension catheter (Video 5). 


\section{Cureus}

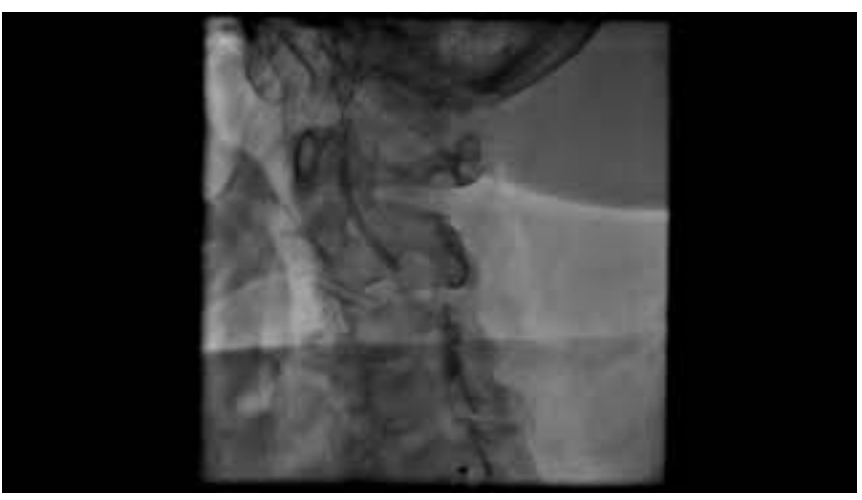

\section{VIDEO 5: 2.5mm balloon advanced into guide extension}

catheter

View video here: https://youtu.be/tMrWuUzth7c

Balloon-assisted tracking of the guide extension catheter was performed into the left ICA beyond the point where the retrieval catheter was hanging up (Video 6).

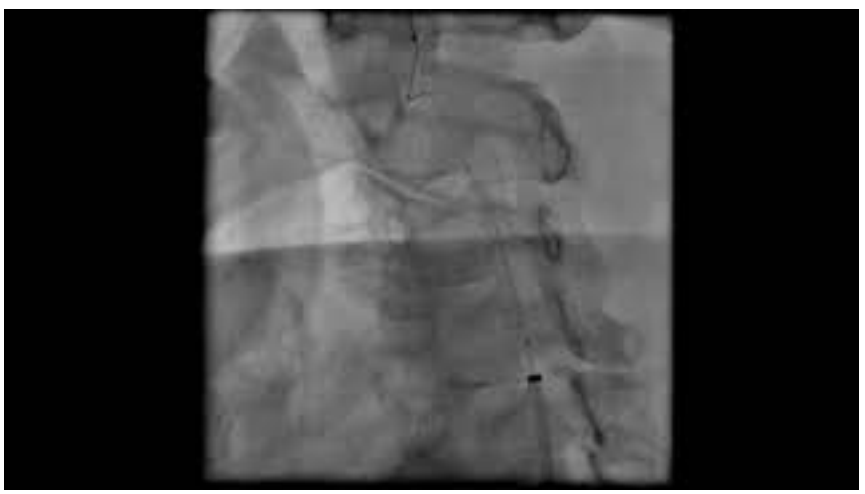

\section{VIDEO 6: Balloon assisted tracking of guide extension catheter into left ICA}

View video here: https://youtu.be/il6Ss3G7oKw

After this, advancing the retrieval catheter into the guide extension was easy and the filter was removed uneventfully.

Due to some focal weakness in the left upper extremity, a CTA of head and neck was performed which showed a small hemorrhagic transformation within the previous right occipital infarct. On discharge, the patient recovered completely and left the hospital with no neurological deficits.

\section{Discussion}

The 30-day risk for stroke is higher with carotid stenting than with CEA [1]. To reduce stroke risk, there is a need for an embolic protection device during CAS. Theron J et al. performed the first carotid artery angioplasty with a distal balloon occlusion system EPD in 1990 [2]. Studies have demonstrated EPD use leads to a decrease in 30-day stroke rate [3]. The three categories of EPDs available are flow preservation devices, distal occlusion devices, and proximal protection devices. Table 1 reviews the two types of distal protection devices and their pros and cons. 


\section{Cureus}

Filters:

1. Preserve antegrade flow

2. Used in the majority of cases worldwide

3. May get clogged

4. Permit passage of small-sized microparticles depending on the pore size of the filter

5. Can cause carotid dissection, embolize, and break or tear

\section{Balloons:}

1. Antegrade flow interrupted

2. Preferred in pre-occlusive lesions

3. Do not permit angiography due to stagnant contrast column

4. Risk of intolerance when collateral circulation is inadequate

5. Can cause carotid dissection, and could tear, embolize or break

\section{TABLE 1: Distal protection devices}

Proximal protection devices are recommended for thrombus-containing lesions or in severely symptomatic lesions where even minimal manipulation of the lesion while initial wiring can cause a substantial risk for stroke. However, their downside is the risk of CCA injury, cerebral blood flow reversal, carotid vacuum effect leading to elongation, and constriction of deployed stent and their large profile [1].

Based on a large retrospective multi-center study, the use of EPDs is associated with a lower risk of adverse procedural events and there was no significant difference in adverse procedural risks between the different devices and types [4]. The device used in this case was the Accunet distal filter (Abbot Vascular, Santa Clara, CA). Distal filters offer only selective protection as particles <100 um can escape [1]. All EPDs are associated with vasospasm, arterial dissection, and equipment failure and run the risk of difficult retrieval.

Techniques to retrieve trapped filters have included external carotid compression, rotation of the head to the contralateral side to change carotid angulation, and use of different catheters like the vertebral and JR-four [5-8]. In this case, none of these techniques were successful. Thinking outside the box enabled the operators to use a technique common in transradial angiography and apply it effectively. This saved the patient the need for open surgery to retrieve the filter, which has also been described as a last resort [9-10]. If the filter were to break off and migrate to the intracranial circulation, conservative management may be the only option [11].

Appropriate patient selection and choosing an appropriate EPD for an individual case can mitigate the risk of retained devices. Calcified plaques and tortuosity index $>80^{\circ}$ are associated with difficult retraction. Three-dimensional imaging can help in identifying potentially tricky situations. Difficult retrievals of EPDs lead to significantly longer procedural times and higher complications [12].

\section{Conclusions}

EPDs are mandatorily required to be used with CAS to decrease stroke during CAS but carry an inherent risk of micro emboli mediated stroke, transient ischemic events, cognitive decline, vascular injury, difficult retrieval. Thorough knowledge of rescue and salvage techniques with EPD complications is critical. Cross-pollinated knowledge between different specialties can 
help disseminate these tricks and techniques.

\section{Additional Information \\ Disclosures}

Human subjects: Consent was obtained by all participants in this study. Conflicts of interest: In compliance with the ICMJE uniform disclosure form, all authors declare the following:

Payment/services info: All authors have declared that no financial support was received from any organization for the submitted work. Financial relationships: All authors have declared that they have no financial relationships at present or within the previous three years with any organizations that might have an interest in the submitted work. Other relationships: All authors have declared that there are no other relationships or activities that could appear to have influenced the submitted work.

\section{Acknowledgements}

Dr. Ashish Pershad, M.D Program Director, Interventional Fellowship Program Cavanagh Heart Center at Banner University Medical Center Phoenix, AZ 85006 Abhishek C. Sawant, M.D., M.P.H. Interventional Cardiology Fellow, Department of Medicine Banner University Medical Center, Phoenix, AZ 85006

\section{References}

1. Mousa YA, Campbell EJ, AbuRahma FA, Bates CM: Current update of cerebral embolic protection devices. J Vasc Surg. 2012, 56:1429-1437. 10.1016/j.jvs.2012.05.077

2. Theron J, Courtheoux P, Alachkar F, Bouvard G: New triple coaxial catheter system for carotid angioplasty with cerebral protection. Am J Neuroradiol. 1990, 11:869-874.

3. Veselka J, Cerná D, Zimolová P, et al.: Feasibility, safety, and early outcomes of direct carotid artery stent implantation with use of the filterwire EZ embolic protection system. Catheter Cardiovasc Interv. 2009, 73:733-738. 10.1002/ccd.21936

4. Iyer V, de Donato G, Deloose K, et al.: The type of embolic protection does not influence the outcome in carotid artery stenting. J Vasc Surg. 2007, 46:251-256. 10.1016/j.jvs.2007.04.053

5. Nii K, Nakai K, Tsutsumi M, et al.: A manual carotid compression technique to overcome difficult filter protection device retrieval during carotid artery stenting. J Stroke Cerebrovasc Dis. 2015, 24:210-214. 10.1016/j.jstrokecerebrovasdis.2014.08.022

6. Daugherty WP, White JB, Cloft HJ, Kallmes DF: Rescue retrieval of angioguard embolic capture system after failure of capture sheath retrieval in carotid angioplasty and stenting. Am J Neuroradiol. 2008, 29:1594-1595. 10.3174/ajnr.A1118

7. Ganim RP, Muench A, Giesler GM, Smalling WR: Difficult retrieval of the EPI filterwire with a 5 french FR4 coronary catheter following carotid stenting. Catheter Cardiovasc Interv. 2006, 67:309-311. 10.1002/ccd.20525

8. Hornung M, Franke J, Bertog SC, Gafoor S, Grunwald I, Sievert H: Initial experience using the gore embolic filter in carotid interventions. J Invasive Cardiol. 2016, 28:334-339.

9. Page P, Niemann D, Son C, Li Y: Retained distal protection device during carotid artery stenting necessitating carotid endarterectomy: a complication and management considerations. Surg Neurol Int. 2018, 9:123. Accessed: 1/23/19:

http://surgicalneurologyint.com/surgicalint-articles/retained-distal-protection-deviceduring-carotid-artery-stenting.... 10.4103/sni.sni_32_18

10. Li T, Zha Y, Bo L, Wirthlin DJ, Zhang Q: Surgical management for retained distal embolic protection device and fractured guidewire after carotid artery stenting. J Surg Case Rep. 2016, 2016:Accessed: 1/23/19: https://academic.oup.com/jscr/article/2016/6/rjw105/2222504. $10.1093 /$ jscr/rjw105

11. Tocco-Tussardi I, Kulyk C, Vindigni V, Avruscio G: Dislocation of a cerebral protection device component during carotid stenting: a case report of favorable outcome from conservative management after failure of retrieval. Int J Surg Case Rep. 2018, 42:254-257.

10.1016/j.ijscr.2017.12.032 


\section{Cureus}

12. Lian X, Liu W, Li M, et al.: Risk factors and complications associated with difficult retrieval of embolic protection devices in carotid artery stenting. Cardiovasc Intervent Radiol. 2012, 35:43-48. 10.1007/s00270-011-0117-y 